\title{
Expectancy Theory and Job Behavior ${ }^{1}$
}

\author{
EDWARD E. LAWLER III ${ }^{2}$ \\ University of Michigan
}

AND

J. Lloyd SutTle

Yale University

\begin{abstract}
Job attitude and behavior data were collected over the period of a year for 69 managers in a retail sales organization. Expectancy attitudes were found to be significantly related to some measures of effort and performance. However, weighting expectancy attitudes by valence measures did not increase the ability of expectancy attitudes to predict behavior. Crosslagged correlational analyses were done, but they provided little support for the view that expectancy attitudes cause performance. Ability and role perception measures were combined with the expectancy measures in order to predict performance, and this led to a significant multiple correlation with performance. The implications of these findings for the further development and testing of expectancy theory are discussed.
\end{abstract}

Expectancy theory has evolved in recent years as a basic paradigm for the study of human attitudes and behavior in work and organizational settings. A number of expectancy-type models have been stated, and they have been frequently used as theoretical and operational definitions of motivation. Although the exact form of the expectancy models described by different writers has varied considerably, most of these variations have been due more to differences in terminology than to conceptual disagreements (Heneman \& Schwab, 1972).

Vroom's (1964) instrumentality theory represents the first attempt to use cognitively-oriented assumptions as the basis for a general theory of work motivation. He defines motivation as the "force" impelling a person to perform a particular action, as determined by the interaction of (a) the person's expectancy that his act will be followed by a particular outcome, and (b) the valence of that (first-level) outcome. This valence,

${ }^{1}$ The authors thank J. R. Hackman and T. Taber for their helpful comments on an earlier version of this paper. The continuing support of E. Fitzgerald and F. Smith made this project possible.

${ }^{2}$ Work on the project was completed while E. Lawler was a Visiting Fellow at the Battelle Seattle Research Center, Seattle, Washington. 
in turn, is a function of "the valences of all other (second-level) outcomes and .... (the first-level outcomes) instrumentality for the attainment of these other outcomes (p. 17)." First-level outcomes are the direct result of behavior (e.g., performing at a certain level, entering a certain work role), and they achieve their valence through their instrumentality for the securing of second-level outcomes (e.g., pay, promotion, recognition), which may have a valence in and of themselves or which may have valence because they lead to still other outcomes.

Following Vroom, a number of writers, most notably Graen (1969), Lawler (1971), Lawler and Porter (1967), and Porter and Lawler (1968), have developed their own expectancy theories. Their major criticisms of Vroom's model stem from its lack of explicitness in defining and distinguishing between actions and outcomes, and between the different types of expectancies associated with each (Campbell, Dunnette, Lawler $\&$ Weick, 1970).

Lawler (1971) has developed an expectancy model of behavior which tries to account for these criticisms and the recent research that has been done on expectancy theory. As shown in Fig. 1, it makes a distinction between the expectancy that effort will lead to the successful performance of a behavioral action. (Effort $\rightarrow$ Performance, $\mathrm{E} \rightarrow \mathrm{P}$ expectancy or Expectancy I), and the expectancy that this action will produce outcomes (Performance $\rightarrow$ Outcome, $\mathrm{P} \rightarrow \mathrm{O}$ expectancy or Expectancy II).

Overall, this expectancy model defines motivation as a function of the combination of the following variables: the perceived likelihood that effort toward a behavioral or task goal will lead to the successful accomplishment of that goal $(\mathrm{E} \rightarrow \mathrm{P})$, the likelihood that the successful accomplishment of the behavior goal will result in the securing of out-

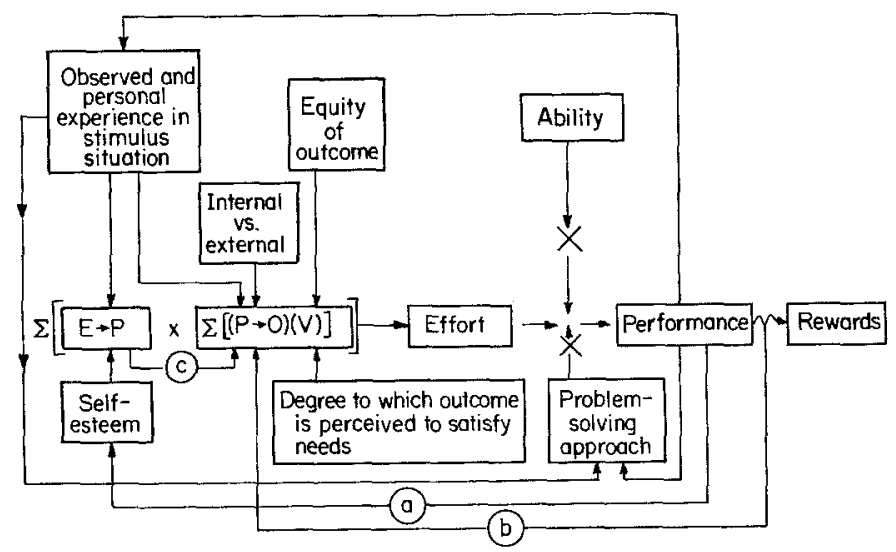

Fig. 1. The expectancy model of motivation. 
comes or rewards $(\mathrm{P} \rightarrow \mathrm{O})$, and the valence (V) of these outcomes. Unlike most previous models this model also specifies what determines the type of $\mathrm{E} \rightarrow \mathrm{P}$ and $\mathrm{P} \rightarrow \mathrm{O}$ beliefs that people have.

The model also argues that job behavior is a joint function of ability, role perceptions and motivation. Maier (1955) has defined behavior as a result of the multiplicative interaction of motivation and ability. Lawler and Porter (1967) added the concept of role perceptions, defined as "the kinds of activities and behavior the individual feels he should engage in to perform his job successfully (p. 130)."

A number of studies have been done in work and organizational settings that test aspects of the kind of expectancy model of behavior that has been presented by Lawler (1971). Heneman and Schwab (1972) have recently reviewed nine such studies. As they point out, the studies offer general support for the model. In addition to the nine studies eited by Heneman and Schwab, at least nine other studies have attempted to test the validity of the expectancy theory approach, and they also provide data which are basically supportive of expectancy-type models. As is

TABLE 1

Previous Expectancy Theory Researoh

\begin{tabular}{|c|c|c|c|c|}
\hline Study & $\begin{array}{l}\text { Significant } \\
\text { expectancy } \\
\text { behavior } \\
\text { relationship } \\
\text { found }\end{array}$ & $\begin{array}{l}\text { Test differ- } \\
\text { ent forms } \\
\text { of model }\end{array}$ & $\begin{array}{l}\text { Test for } \\
\text { how ability } \\
\text { and other } \\
\text { factors } \\
\text { influence } \\
\text { behavior }\end{array}$ & $\begin{array}{c}\text { Causal } \\
\text { test }\end{array}$ \\
\hline $\begin{array}{l}\text { Georgopoulos, Mahoney, \& Jones } \\
\text { (1957) }\end{array}$ & Yes & Yes & No & No \\
\hline Lawler (1964) & Yes & Yes & No & No \\
\hline Spitzer (1964) & Yes & Yes & No & No \\
\hline Lawler (1966a) & Yes & No & Yes & No \\
\hline Lawler (1966b) & Yes & No & No & No \\
\hline Galbraith \& Cummings (1967) & Yes & Yes & No & No \\
\hline Lawler \& Porter (1967) & Yes & Yes & Yes & No \\
\hline Hackman \& Porter (1968) & Yes & Yes & No & No \\
\hline Lawler (1968) & Yes & Yes & No & Yes \\
\hline Porter \& Lawler (1968) & Yes & Yes & Yes & No \\
\hline Graen (1969) & Yes & Yes & No & No \\
\hline Evans (1970) & Yes & Yes & No & No \\
\hline Gavin $(1970)$ & Yes & Yes & No & No \\
\hline Goodman, Rose, \& Furcon (1970) & Yes & No & Yes & No \\
\hline Hackman \& Lawler (1971) & Yes & No & No & No \\
\hline House (1971) & Yes & Yes & No & No \\
\hline Schuster, Clark, \& Rogers (1971) & Yes & Yes & No & No \\
\hline Mitchell \& Albright (in press) & Yes & Yes & No & No \\
\hline
\end{tabular}


shown in the first column in Table 1 , the studies designed to test expectancy theory have consistently found that expectancy type attitude measures are significantly correlated with measures of job performance.

Despite the fact that at least eighteen studies have tried to test the expectancy theory approach to explaining job behavior, a number of crucial aspects of the theory remain untested and a number of important questions remain unanswered. As is shown in the second column in Table 1, a majority of the studies have tried to test the relative validity of different forms of the expectancy model. That is, they have tried to determine such things as whether or not multiplying expectancy attitudes times valence attitudes leads to improved prediction of behavior. Unfortunately, few studies have measured all the different kinds of attitudes that are necessary for a complete test, and as a result the tests so far have been inadequate. At this point it simply is not clear whether the kind of expectancies that are specified in models like those of Vroom and Lawler do in fact combine to influence motivation in the way the models argue they should.

Based upon the models, seven conceptually different variables, some of which are multiplicative interactions of expectancies and valences, can be defined on an a priori basis. These seven variables, the concepts which they were developed to represent, and the formulas used to compute them are as follows:

$\mathrm{E} \rightarrow \mathrm{O}$, Effort $\rightarrow$ Outcome Associations: A measure of the degree to which effort is seen to result in such outcomes as pay and promotion.

$\Sigma[(\mathrm{E} \rightarrow \mathrm{O})(\mathrm{V})]$, Effort $\rightarrow$ Outcome Associations weighted by Valences: A measure of Force, or motivation, computed as the sum or average of the $\mathrm{E} \rightarrow \mathrm{O}$ expectancies when each outcome is multiplied by its valence.

$\mathrm{E} \rightarrow \mathrm{P}$, Effort $\rightarrow$ Performance Association: A measure of the belief that effort will lead to good performance.

$\Sigma(P \rightarrow O)$, Performance $\rightarrow$ Outcome Associations: A measure of Expectancy II, computed as the sum or average of beliefs which link performance with first-level outcomes.

$\Sigma[(\mathrm{P} \rightarrow \mathrm{O})(\mathrm{V})], \quad$ Performance $\rightarrow$ Outcome Associations weighted by Valences: A measure similar to $\mathrm{P} \rightarrow \mathrm{O}$ expectancies, except that each outcome is multiplied by its valence.

$(\mathrm{E} \rightarrow \mathrm{P}) \quad \Sigma(\mathrm{P} \rightarrow \mathrm{O})$, Expectancy I multiplied by Expectancy II: computed as the product of the $\mathrm{E} \rightarrow \mathrm{P}$ and $\mathrm{P} \rightarrow \mathrm{O}$ variables.

$(\mathrm{E} \rightarrow \mathrm{P}) \quad \Sigma[(\mathrm{P} \rightarrow \mathrm{O})(\mathrm{V})]$, Motivation: A measure of the concept of motivation, computed as the product of the $\mathrm{E} \rightarrow \mathrm{P}$ and the $(\mathrm{P} \rightarrow \mathrm{O})$ (V) variables. 
By correlating these seven variables with each other and with job behavior, it should be possible to gain insights into the structural characteristics of the model and of employee attitudes and beliefs. This kind of analysis is badly needed if the models are to be further developed and tested.

The analysis reported in the third column of Table 1 shows that few studies have tested predictions concerned with how ability, motivation, and role perception combine to determine performance. Gavin (1970) and Heneman and Schwab (1972) have noted the lack of research studies of this type, and the uncertainties that remain about the interactions among the various causes of behavior. As they point out, the potential usefulness of expectancy models can only be determined once the roles of motivation, ability and role perceptions in the determination of job performance can be better specified.

Expectancy theory proposes a causal relationship between expectancy attitudes and motivation. As is shown in the fourth column in Table 1 , only one of the previous studies was concerned with testing the causal aspects of this model (Lawler, 1968). This study did provide support for the model. Since this is a crucial aspect of expectancy theory, further testing is badly needed. Testing causal relationships in a nonexperimental field setting is more difficult than examining such relationships in a laboratory experiment, but a partial test is possible through the use of longitudinal data and correlational analysis (Simon, 1954; Blalock, 1962; Pelz \& Andrews, 1964; Campbell \& Stanley, 1963). They can be used to yield insights into both the strength and the direction of relationships between attitudes and behavior. This method is limited since it cannot prove causality (Rozelle \& Campbell, 1969). However, if it fails to yield data which supports causation, it is very likely that the kind of causation which is hypothesized does not exist. This type of correlational analysis was described by Lawler and Suttle as follows: Two variables, $X$ and $Y$, are each measured at two different points in time, $t_{1}$ and $t_{2}$. The six possible intercorrelations are then computed, as illustrated in Fig. 2. Logically, if $X$ causes $Y$, the correlation between $X_{t 1}$ and $Y_{t_{2}}\left(r_{2}\right)$ should be strong, while the correlation between $Y_{t 1}$ and $X_{t 2}\left(r_{3}\right)$ should be weak. Conversely, if $Y$ causes $X$, then the relationship between $Y_{t 1}$ and $X_{\mathrm{t} 2} \quad\left(\mathrm{r}_{3}\right)$ should be stronger than the corresponding relationship between $X_{t 1}$ and $Y_{t 2}\left(r_{2}\right)$. In the present study, the causal variable (Variable $\mathrm{X}$ in Fig. 2) is the individual's expectancy attitudes, and the dependent variable (Variable $Y$ ) is his motivation. Thus, high expectancies at $t_{1}$ that effort will lead to valued rewards should be associated with high effort at $t_{2}$.

The relationship between expectancies and effort may be more com- 


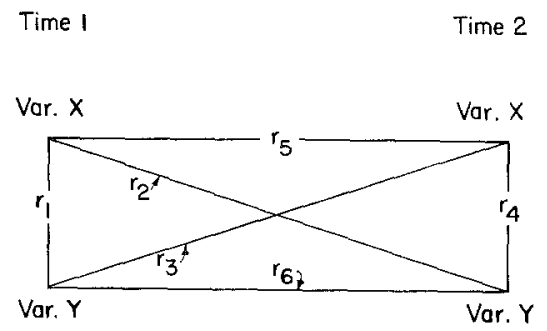

$$
\begin{aligned}
& r_{5} \text { and } r_{6} \text { : Reliability measures of Var. } X \text { and Var. } Y \\
& r_{2}>\left(r_{1}=r_{4}\right)>r_{3}=>\operatorname{Var} . X \text { coused Var. } Y \\
& r_{3}>\left(r_{1}=r_{4}\right)>r_{2}=>\text { Var. } Y \text { caused Var. } X
\end{aligned}
$$

FIG. 2. Cross-lagged panel correlational model.

plex than this simple one-way causality hypothesis would suggest, however, and the time lag between $t_{1}$ and $t_{2}$ plays a crucial role in this relationship. In many cases there is some delay before $\mathrm{X}$ effects $\mathrm{Y}$; and, unless there is a $t_{1}$ and $t_{2}$ appropriately separated, insignificant results will be obtained. Lawler (1971) has indicated that both a direct causal relationship between expectancies and effort, and a weaker causal relationship between effort and expectancies may exist. In his model, there is a feedback from the individual's effort, the behavior which results from this effort, and the rewards which result from this behavior to his expectancy-attitudes. Conceptually, however, this two-way causal relationship is not totally reciprocal, for effort influences expectancies only indirectly, and, thus, after a longer time lag and to a lesser degree.

Testing this more complex two-way relationship is difficult in a field setting with survey data, but it can be partially tested by collecting data from groups with different time lags between the collection of the $t_{1}$ and $t_{2}$ data. By comparing the causal analyses of these groups, it should be possible to gain insights not only into the length of the appropriate time lag for the expectancy attitude's effect on effort, but also into the validity of the expanded expectancy model with its two-way causal relationships.

\section{METHOD}

The data for the present study were obtained as part of a larger study, some of the results of which have been reported in an earlier article by the same authors (Lawler \& Suttle, 1972). 


\section{Sample}

The sample consisted of 69 department managers in six retail stores. They supervised 2-8 salesmen and were on a pay incentive plan. Their median age was 41.6 , and their median salary was $\$ 11,286$ a year. Only $50 \%$ had more than a high school education. Their median time with the store was 13.2 years and their median time in position was 3.6 years. The sample resembles other larger samples of middle and lower level managers (e.g., Porter, 1961, 1962) which have been used in studies of managerial attitudes.

\section{Procedure}

One of the researchers met in small groups with all of the participants in the study. He was introduced by a member of management and then he explained that he was doing a research project and that their organization had agreed to cooperate but that their participation was voluntary. The subjects were told that their organization would receive the overall results of the study but that the data from participants would be combined in the feedback reports. The researcher asked for questions and in most groups a lively discussion followed. The questions typically centered around why the researcher was doing the study and what impact it might have on the organization. When the questions were exhausted, the researcher asked the subjects to complete the questionnaire while he waited. He also pointed out that at some later time he would again be asking them to complete the questionnaire.

Six months later the researcher met with a random subsample of half of the subjects from the organization. At that meeting he asked them to complete the same questionnaire. He stressed that he was not trying to test their memory but that he was interested in seeing how they now felt about their jobs. One year after the original meeting the researcher met with the remaining subjects. This meeting was like the one that had been held six months earlier with the other half of the sample. Of the 69 subjects who began the study, second questionnaires were obtained from 61. In most cases where a second questionnaire could not be obtained, the person had left the organization or had been transferred.

\section{Questionnaire}

The attitudinal variables in the present study were measured in three sections of a six-part questionnaire. Measures of the variables (expectancies and valences) were developed which were as close as possible to their conceptual definitions.

Expectancies. The questionnaire contained 38 items, which described 
one of the three kinds of expectancies discussed in the introduction. The printed instructions for this section were as follows:

Below you will see a number of pairs of factors that look like this:

- Warm weather $\rightarrow$ Sweating

You are to indicate on the line to the left of each pair how often it is true for you personally that the first factor leads to the second on your job. In doing this, please use the following numbers to represent different feelings about how frequently the first factor leads to the second.

$\begin{array}{ll}1 \text { Never } & 5 \text { Often } \\ 2 \text { Seldom } & 6 \text { Usually } \\ 3 \text { Occasionally } & 7 \text { Always } \\ 4 \text { Sometimes } & \end{array}$

The respondents were then given a list of 38 items, of which two measured $\mathrm{E} \rightarrow \mathrm{P}$ expectancies, eighteen measured $\mathrm{P} \rightarrow \mathrm{O}$ expectancies, and eighteen measured $\mathrm{E} \rightarrow \mathrm{O}$ expectancies. Effort was represented by the term "Working hard," and in the $\mathrm{P} \rightarrow \mathrm{O}$ items performance was represented by "Good job performance." Eighteen different outcomes were then linked to these two terms. Typical $\mathrm{E} \rightarrow \mathrm{P}, \mathrm{P} \rightarrow \mathrm{O}$, and $\mathrm{E} \rightarrow \mathrm{O}$ items, respectively, were:

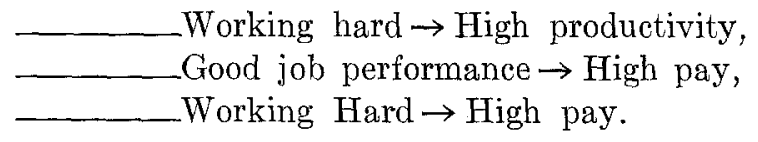

A complete list of the 38 items is presented in Table 6 .

Valences. In addition to expectancies about the eighteen outcomes, the respondents' preference or valence for each outcome was also measured. The valences of the effort variable ("working hard") and the two performance variables ("good job performance" and "high productivity") were also measured. The instructions for this part of the questionnaire stated:

Listed below are a number of things that you can either do in your job or can receive from your job. For each one, would you please indicate how desirable it is to you.

Please use the following numbering system in order to indicate how desirable you consider each item to be.

1 Extremely desirable

2 Very desirable

6 Moderately undesirable

3 Desirable

7 Undesirable

4 Moderately desirable

8 Very undesirable

5 Neutral

9 Extremely undesirable

A listing of the 21 items followed.

In order to clarify the analyses performed on these data, the valence 
scores on the scale were reversed, so that low numbers would represent low valences and high numbers, high valences. These reversed valences are used in Table 2, which shows the means and standard deviations of the 21 valence items.

Expectancy scores. The 38 expectancy items and the 21 valence items were used to calculate the seven "expectancy scores" described in the introduction. The means and standard deviations of these seven scores are shown in Table 3.

Role perceptions. The questionnaire also measured the respondent's perception of his own job behavior, and his beliefs about what was successful behavior on his job. These were measured by the inner-other scale. It was developed by Porter (1964) based on the work of Riesman (1950) and Whyte (1956). Its appropriateness as an operational definition of role perception has been discussed by Porter and Lawler (1968). Two studies (Lawler \& Porter, 1967; Porter \& Lawler, 1968) have found that it is related to job performance in managerial jobs.

TABLE 2

Means and Standard Deviations of the Valences of the 21 Odtcomes

\begin{tabular}{lcc} 
& \multicolumn{2}{c}{$\begin{array}{c}\text { Retail org. } \\
(n=69)\end{array}$} \\
\cline { 1 - 2 } & \multicolumn{1}{c}{ Outcomes } & $\sigma$ \\
\hline Working hard (Effort) & 7.43 & 0.99 \\
High productivity (Task Goal) & 7.94 & 0.99 \\
Good job performance (Task Goal) & 8.36 & 0.87 \\
Giving help to others & 7.75 & 0.79 \\
Personal growth and development & 8.16 & 0.79 \\
Feelings of accomplishment & 8.25 & 0.73 \\
Greater chances for independent thought and action & 7.59 & 1.16 \\
Time at work passing fast & 6.70 & 1.47 \\
Offering good service & 8.10 & 0.76 \\
Feelings of security & 7.97 & 0.98 \\
Receiving more compliments & 6.48 & 1.19 \\
Respect from your boss & 8.35 & 0.72 \\
Special awards and recognition & 7.04 & 1.18 \\
High pay & 8.22 & 0.85 \\
Promotion & 8.20 & 0.86 \\
Pay raise & 8.29 & 0.74 \\
Respect from other employees & 7.72 & 0.95 \\
Setting too high standards for yourself & 5.87 & 1.88 \\
Setting too high standards for others & 4.83 & 1.69 \\
Being tired from hard work & 4.96 & 1.86 \\
Fewer chances to make friends & 4.20 & 1.88 \\
\hline
\end{tabular}


TABLE 3

Means and Standard Deviations of the Seven Expectancy Scores

\begin{tabular}{lrr}
\hline Expectancy score & \multicolumn{1}{c}{$\bar{x}$} & \multicolumn{1}{c}{$\sigma$} \\
\hline $\mathrm{E} \rightarrow 0$ & 4.83 & 0.60 \\
$\Sigma[(\mathrm{E} \rightarrow 0)(\mathrm{V})]$ & 36.03 & 5.95 \\
$\mathrm{E} \rightarrow \mathrm{P}$ & 5.87 & 0.92 \\
$\Sigma(\mathrm{P} \rightarrow 0)$ & 5.03 & 0.54 \\
$\Sigma[\mathrm{P} \rightarrow 0)(\mathrm{V})]$ & 37.59 & 5.71 \\
$(\mathrm{E} \rightarrow \mathrm{P}) \Sigma(\mathrm{P} \rightarrow 0)$ & 29.67 & 6.31 \\
$(\mathrm{E} \rightarrow \mathrm{P}) \Sigma[(\mathrm{P} \rightarrow 0)(\mathrm{V})]$ & 222.43 & 56.18 \\
\hline
\end{tabular}

The inner-other scale asked subjects to rank twelve traits on two dimensions: how well they describe the subject's behavior on the job and how important they are for job success. The following twelve traits were used.

$\begin{array}{ccc}\text { Inner-Directed Cluster } & \text { Other-Directed Cluster } & \text { Dummy Traits } \\ \text { Forceful } & \text { Cooperative } & \text { Intelligent } \\ \text { Imaginative } & \text { Adaptable } & \text { Efficient } \\ \text { Independent } & \text { Cautious } & \\ \text { Self-Confident } & \text { Agreeable } & \\ \text { Decisive } & \text { Tactful } & \end{array}$

The subject's inner-other score, or measure of role perception, was then computed by ranking the ten relevant traits in the reverse order of the subject's ranking, i.e., from 0 for the highest ranked (least descriptive) trait to 9 for the lowest ranked (most descriptive) trait. These reversed rankings of the five traits in the inner-directed cluster were summed, giving a measure on which a low score indicates low inner-directedness and high other-directedness. The average score was 23.72 for the descriptions of job behavior (JB) and 25.16 for importance for job success (JS).

\section{Ability Measures}

Ability measures consisted of an "in house" test, the Thurstone Test of Mental Alertness (Thurstone \& Thurstone, 1952), which was given at the time of the employees entrance into the organization. The test yielded a verbal, a quantitative, and a total intelligence score. Previous research has shown that these scores are predictive of performance in this organization (Campbell, Dunnette, Lawler \& Weick, 1970). The average ability scores were $37.96,28.53$, and 66.49 , respectively. 


\section{Intercorrelations among Predictor Variables}

Most expectancy models hypothesize that a combination of expectancies, role perceptions, and abilities determine behavior, or work performance. Although the exact form of this combination varies in different models, the two types of combinations which are most often mentioned are the additive and the multiplicative. In the present paper, therefore, the expectancy $(\mathrm{E} \rightarrow \mathrm{P}) \quad \Sigma[(\mathrm{P} \rightarrow \mathrm{O})(\mathrm{V})]$, role perception (JB), and total ability measures were both summed and multiplied. Table 4 shows the interrelations among these variables and their combinations.

\section{Criteria Measures}

Two types of performance measures were collected for the subjectssubjective performance rankings by the subject himself, by his boss, and by his peers, and objective sales data.

Subjective performance rankings. Each subject completed an "Employee Ranking Form" in which he was asked to rank himself and his peers on two different traits-overall job performance and effort put into the job. The subject's supervisor was also asked to provide these rankings. The rankings were then converted to standard scores with a mean of 50 and a standard deviation of 10 . Where a subject was ranked by more than one peer, an average peers' ranking was computed.

Objective performance rankings. Sales data were collected to provide

TABLE 4

Intercorrelations of Predictors $(n=69)$

\begin{tabular}{|c|c|c|c|c|c|c|c|}
\hline & \multirow[b]{2}{*}{ Expect. } & \multirow{2}{*}{$\begin{array}{c}\text { Thurstone } \\
\text { total }\end{array}$} & \multirow{2}{*}{$\begin{array}{c}\text { Thurstone } \\
\text { verbal }\end{array}$} & \multirow{2}{*}{$\begin{array}{c}\text { Thurstone } \\
\text { quan. }\end{array}$} & \multicolumn{2}{|c|}{$\begin{array}{c}\text { Role } \\
\text { perceptions }\end{array}$} & \multirow{2}{*}{$\begin{array}{c}\text { Sum of } \\
\text { the } \\
\text { variables }\end{array}$} \\
\hline & & & & & JB & JS & \\
\hline $\mathrm{T}$ & -.23 & & & & & & \\
\hline V & -.20 & $.89^{* *}$ & & & & & \\
\hline $\mathrm{Q}$ & -.23 & $83^{* *}$ & $.51^{* *}$ & & & & \\
\hline$J B$ & -.11 & .05 & -.10 & $.25^{*}$ & & & \\
\hline JS & $-.25^{*}$ & .06 & -.04 & .19 & $.63^{* *}$ & & \\
\hline $\begin{array}{l}\text { Sum of the } \\
\text { variables }\end{array}$ & $.83^{* *}$ & .02 & -.02 & .03 & $.42^{* *}$ & .10 & \\
\hline $\begin{array}{l}\text { Product of the } \\
\text { variables }\end{array}$ & $.38^{* *}$ & $.62^{* *}$ & $.64^{* *}$ & $.39 * *$ & $.39 * *$ & .13 & $.72^{* *}$ \\
\hline
\end{tabular}

$* p<.05$ two tail.

** $p<.01$ two tail. 
an objective measure of the subject's performance. These data took the form of departmental sales figures collected from each of the departments managed by one of the subjects. They were collected over the 13 -month period during which the study was in progress. A number of irrelevant biases influence any "raw" sales data. Thus, they had to be transformed in several ways in order to remove those variations in sales which were obviously not due to variations in the performance of the managers.

First, in order to reduce the unreliability of the data caused by random monthly influences, the sales data were averaged over three-month periods. According to the time intervals incorporated into the design of the study, an average sales score was obtained for the first (months 1-3), middle (months 6-8), and last (months 11-13) three month periods during which the study was taking place. These averages were then converted to "percentage of store sales" figures in order to remove the effects of one store being larger than other stores, or being in an advantaged location, etc. Finally, in order to reduce the effects of one department having an unfair or irrelevant advantage over other departments in the same store (e.g., size, store policy, etc.), the percentage figures were converted to interstore rankings $(6=$ highest sales, $1=$ lowest). Thus, each manager had an objective performance score between 1 and 6 which indicated how well his department did in the context of his store relative to how identical departments did in the context of other stores.

A multitrait (effort and performance), multirater (self, boss, and peers), multimethod (subjective ratings and objective sales data) matrix for the different types of criteria measures obtained was constructed. There was little tendency for the rankers to discriminate between effort and performance. All of the correlations between effort rankings and performance rankings for a single rater were significant at the 01 level or better, and average .71. The three different raters tended to agree with each other on their rankings for the same trait and each rater's rankings for one trait were strongly related to the other raters' rankings for different traits. In other words, although the correlations between the rankings of each trait by two different raters were generally high and significant, these correlations were not significantly different from the other correlations. The boss and peer rankings tended to agree most strongly ( $r=.65$ and .79 for the two traits), while the self rankings showed less (but still significant) agreement with boss and peer rankings. Finally, the rankings were not strongly related to the sales performance criteria. In short, the criteria possess some of what Campbell and Fiske (1959) term convergent validity but little discriminant validity. 


\section{RESULTS}

\section{Structural Analysis of Expectancy Attitudes}

In order to determine if the subjects distinguished among the different types of expectency items that were included among the 38 to which they responded, their responses were factor analyzed. Table 5 shows the results of this principal components factor analysis rotated to three factors by the Varimax criterion (Kaiser, 1958). This table is based on data collected at the beginning of the study. Three readily interpretable factors emerge from these results. These factors are defined not by the type of expectancy (e.g., $\mathrm{E} \rightarrow \mathrm{O}, \mathrm{P} \rightarrow \mathrm{O}$ ), but by the type of outcome or reward involved. Thus, the first factor consists of those items concerned with internally-mediated rewards, the second factor includes those items concerned with externally-mediated rewards, and the third factor consists of those concerned with negatively-valued outcomes. Generally, both the $\mathrm{E} \rightarrow \mathrm{O}$ and $\mathrm{P} \rightarrow \mathrm{O}$ expectancies for a single outcome appear in the same factor. The two items measuring $\mathrm{E} \rightarrow \mathrm{P}$ expectancies load most on the internal rewards factor.

The strength of the subject's expectancies differ across the three factors, as shown by the last two columns in Table 5. The highest expectancies involve internally-mediated rewards, while the lowest ones involve the negatively-valued outcomes.

Table 6 shows the intercorrelation of the seven conceptually different variables defined a priori by expectancy theory and the three factors that were defined by the factor analysis. With only a few exceptions, the intercorrelations are significant at the .05 level or better. The highest correlations occur between the expectancies per se and the expectancies weighted by the appropriate valences. The only moderately low correlations among the expectancy measures are between the $\mathrm{E} \rightarrow \mathrm{P}$ and $\mathrm{P} \rightarrow \mathrm{O}$ measures.

\section{Relationship of the Different Structures to Effort}

Table 7 shows the concurrent correlations between the ten different expectancy measures and three different criteria measures, i.e., three different rankings of effort. In this table, the weighted (with $V$ ) and unweighted $(\mathrm{E} \rightarrow \mathrm{P}) \Sigma(\mathrm{P} \rightarrow \mathrm{O})$ measure of motivation yield the highest correlations. At the same time, however, several of the other types of expectancy measures (the simple $\mathrm{E} \rightarrow \mathrm{P}$, or Expectancy $\mathrm{I}$, measure, the $\mathrm{E} \rightarrow \mathrm{O}$ variable, and Factor I) also correlate significantly with effort, and no one of the variables or structures is clearly more valid than the others. This is to be expected, due to the high intercorrelations among these measures. For the remaining analyses, however, the $(\mathrm{E} \rightarrow \mathrm{P})$ 
TABLE 5

Factor Loadings, Means, and Standard Deviations for

Expectancx-Attitude Ittems

\begin{tabular}{|c|c|c|c|c|c|}
\hline \multirow[b]{2}{*}{ Items $^{1}$} & \multicolumn{3}{|c|}{ Factors $^{2}$} & \multirow[b]{2}{*}{$\bar{x}$} & \multirow[b]{2}{*}{$\sigma$} \\
\hline & $I^{a}$ & $\mathrm{II}^{b}$ & III $^{c}$ & & \\
\hline WH $\rightarrow$ Giving help to others & 77 & -11 & -03 & 5.46 & 1.08 \\
\hline WH $\rightarrow$ Personal growth and development & 71 & -07 & 15 & 5.90 & .85 \\
\hline WH $\rightarrow$ High productivity $(\mathrm{E} \rightarrow \mathrm{P})$ & 71 & -08 & 00 & 5.57 & 1.03 \\
\hline GJP $\rightarrow$ Personal growth and development & 68 & -30 & 00 & 5.78 & .91 \\
\hline WH $\rightarrow$ Feelings of accomplishment & 66 & -06 & -12 & 5.97 & .83 \\
\hline $\begin{array}{l}\text { GJP } \rightarrow \text { Greater chances for independent thought } \\
\text { and action }\end{array}$ & 60 & -21 & -09 & 5.39 & 1.13 \\
\hline GJP $\rightarrow$ Time at work passing fast & 60 & 38 & 33 & 5.90 & 1.14 \\
\hline GJP $\rightarrow$ Giving help to others & 58 & -20 & -07 & 5.64 & 1.08 \\
\hline $\begin{array}{l}\text { WH } \rightarrow \text { Greater chances for independent thought and } \\
\text { action. }\end{array}$ & 56 & -24 & -04 & 5.16 & 1.17 \\
\hline $\mathrm{WH} \rightarrow$ Good job performance $(\mathrm{E} \rightarrow \mathrm{P})$ & 54 & -09 & 06 & 5.87 & .92 \\
\hline WH $\rightarrow$ Time at work passing fast & 53 & 38 & 35 & 6.04 & 1.17 \\
\hline GJP $\rightarrow$ Feelings of accomplishment & 51 & -16 & -11 & 6.35 & .70 \\
\hline GJP-Offering good service & 49 & -30 & -14 & 5.77 & 1,13 \\
\hline WH-Feeling of security & 48 & -23 & 03 & 5.45 & 1.26 \\
\hline WH-Receiving more compliments & 46 & -31 & -09 & 4.64 & 1.18 \\
\hline GJP-Respect from your boss & 46 & -44 & -09 & 5.93 & 1.03 \\
\hline GJP-Feeling of security & 40 & -12 & 14 & 5.97 & 1.10 \\
\hline WH-Special awards or recognition & 22 & -77 & 11 & 4.72 & 1.06 \\
\hline WH--High pay & 15 & -75 & 12 & 4.81 & 1.41 \\
\hline WH-Promotion & 28 & -74 & 11 & 4.62 & 1.43 \\
\hline GJP-Promotion & 20 & -73 & -05 & 5.06 & 1.36 \\
\hline GJP_Special awards or recognition & 14 & -72 & -08 & 5.04 & 1.29 \\
\hline GJP-Pay raise & 18 & -72 & 06 & 4.93 & 1.29 \\
\hline WH-Pay raise & 16 & -72 & 12 & 4.54 & 1.37 \\
\hline GJP-High pay & 09 & -65 & 28 & 5.33 & 1.35 \\
\hline WH-Respect from your boss & 37 & -53 & -20 & 5.70 & 1.21 \\
\hline GJP-Respect from other employees & -06 & -51 & 06 & 5.78 & 1.02 \\
\hline WH-Offering good service & 39 & -42 & -10 & 5.43 & 1.33 \\
\hline WH-Respect from other employees & 23 & -39 & 20 & 5.39 & 1.13 \\
\hline GJP-Receiving more compliments & 27 & -33 & -22 & 4.88 & 1.04 \\
\hline WH-Setting too high standards for yourself & 05 & -07 & 75 & 3.28 & 1.94 \\
\hline GJP-Setting too high standards for yourself & 10 & -24 & 74 & 3.33 & 1.89 \\
\hline WH-Setting too high standards for others & 03 & -08 & 68 & 3.20 & 1.55 \\
\hline GJP--Setting too high standards for others & 16 & -08 & 62 & 3.16 & 1.64 \\
\hline GJP-Being tired from hard work & -19 & 10 & 55 & 3.64 & 1.69 \\
\hline WH--Being tired from hard work & -21 & 11 & 52 & 3.80 & 1.58 \\
\hline GJP-Fewer chances to make friends & -29 & -15 & 45 & 2.61 & 1.50 \\
\hline WH-Fewer chances to make friends & -30 & -27 & 42 & 2.90 & 1.54 \\
\hline
\end{tabular}

${ }^{1} \mathrm{WH}=$ working hard; GJP $=$ good job performance.

${ }^{2}$ Rotated by varimax criterion.

a $18 \%$ of variance accounted for.

${ }^{b} 17 \%$ of variance accounted for.

$\therefore 9 \%$ of variance accounted for. 


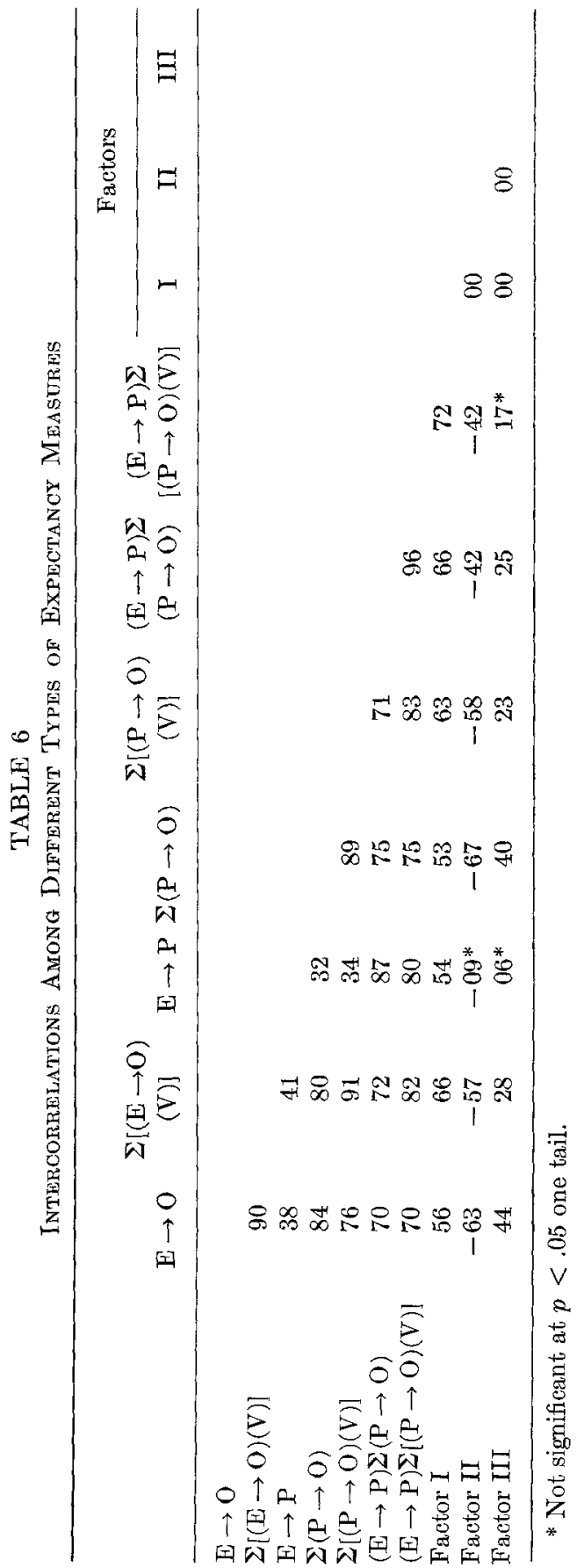


TABLE 7

Correlations Between Rankings of Effort and Different Trpes of Expectancy Measures

\begin{tabular}{lccc}
\hline Expectancy measures & Rank by self & Rank by boss & Rank by peers \\
\hline $\mathrm{E} \rightarrow \mathrm{O}$ & $31^{*}$ & $25^{*}$ & 18 \\
$\Sigma[(\mathrm{E} \rightarrow \mathrm{O})(\mathrm{V})]$ & $34^{* *}$ & $22^{*}$ & 16 \\
$\mathrm{E} \rightarrow \mathrm{P}$ & $37^{* *}$ & $28^{* *}$ & 05 \\
$\Sigma(\mathrm{P} \rightarrow \mathrm{O})$ & $29^{*}$ & 19 & $22^{*}$ \\
$\Sigma[(\mathrm{P} \rightarrow \mathrm{O})(\mathrm{V})]$ & $31^{*}$ & 17 & $20^{*}$ \\
$(\mathrm{E} \rightarrow \mathrm{P}) \Sigma(\mathrm{P} \rightarrow \mathrm{O})$ & $39^{* *}$ & $29^{* *}$ & 15 \\
$(\mathrm{E} \rightarrow \mathrm{P}) \Sigma[(\mathrm{P} \rightarrow \mathrm{O})(\mathrm{V})]$ & $39^{* *}$ & $28^{* *}$ & 16 \\
Factor I & $32^{* *}$ & $27^{* *}$ & 15 \\
Factor II & -07 & -06 & -06 \\
Factor III & 12 & 05 & 15 \\
\hline
\end{tabular}

$* p<.05$ one tail.

${ }^{* *} p<.01$ one tail.

$\Sigma[(\mathrm{P} \rightarrow \mathrm{O})(\mathrm{V})]$ measure will be used as the "best available" measure of motivation.

The data in Table 7 show that although none of the correlations are high, the predicted relationships between expectancies and effort are present. These data also show that the different types of criteria measures do not correlate equally well with the attitude measures. The peer rankings show lower correlations with the independent variables than either the self or the boss rankings.

\section{Causal Analysis}

Static or concurrent correlations cannot test for causality, a more appropriate although not conclusive test for causality is shown in Table 8, where a cross-lagged correlational analysis is reported. Here, it is not only the strength or significance of the correlations that are important, but also their relative sizes. If expectancies do cause effort, then the $r_{2}$ correlations should be higher than the $r_{3}$ correlations: if effort has the stronger effect on expectancies than vice versa, then the $r_{3}$ coefficients should be the larger. Theoretically, the $r_{1}$ and $r_{4}$ correlations should lie between the other two. In light of these requirements for a successful validation of the expectancy model, the data in Table 8 provide weak support for the causal relationships specified by the model.

Table 9 shows the results of a cross-lagged analysis between the motivation measure $(\mathrm{E} \rightarrow \mathrm{P}) \Sigma[(\mathrm{P} \rightarrow \mathrm{O})(\mathrm{V})]$ and three different rankings of performance. As was the case with the causal analysis between the ex- 
TABLE 8

Cross-Lagged Correlations Between the Motivation Measure $(\mathrm{E} \rightarrow \mathrm{P}) \boldsymbol{\Sigma}[(\mathrm{P} \rightarrow \mathrm{O})(\mathrm{V})]$ AND EFFort RaNKINGS

\begin{tabular}{|c|c|c|c|c|c|c|}
\hline \multirow[t]{2}{*}{ Effort rankings } & \multicolumn{3}{|c|}{ Cross-lagged correlations } & \multicolumn{3}{|c|}{ Test-retest correlations } \\
\hline & $r_{1}$ & $r_{2}$ & $r_{3}$ & $r_{4}$ & $r_{5}$ & $r_{6}$ \\
\hline \multicolumn{7}{|c|}{6 months group $(n=35)$} \\
\hline Rank $\times$ self & $46 * *$ & $53^{* *}$ & 11 & -10 & $47^{* *}$ & $77^{* *}$ \\
\hline Rank $\times$ boss & 24 & $44^{*}$ & 28 & 23 & $47 * *$ & $84^{* *}$ \\
\hline Rank $\times$ peers & 23 & 07 & -12 & -21 & $47 * *$ & $71^{* *}$ \\
\hline \multicolumn{7}{|c|}{12 months group $(n=34)$} \\
\hline Rank $\times$ self & $37 *$ & 18 & 32 & 31 & $52 * *$ & $86^{* *}$ \\
\hline Rank $\times$ boss & $32^{*}$ & -05 & 28 & 28 & $52 * *$ & $85^{* *}$ \\
\hline Rank $\times$ peers & 13 & 08 & $43 *$ & 24 & $52 * *$ & $82^{* *}$ \\
\hline
\end{tabular}

$* p<.05$ one tail.

${ }^{* *} p<.01$ one tail.

TABLE 9

Cross-Lagged Correlations Between Expectancies $(\mathrm{E} \rightarrow \mathrm{P}) \Sigma[(\mathbf{P} \rightarrow \mathrm{O})(\mathrm{V})]$ and Performance Rankings

\begin{tabular}{|c|c|c|c|c|c|c|}
\hline \multirow[t]{2}{*}{$\begin{array}{l}\text { Performance } \\
\text { rankings }\end{array}$} & \multicolumn{4}{|c|}{ Cross-Iagged correlations } & \multicolumn{2}{|c|}{$\begin{array}{l}\text { Test-retest } \\
\text { correlations }\end{array}$} \\
\hline & $r_{1}$ & $r_{2}$ & $r_{3}$ & $r_{4}$ & $r_{5}$ & $r_{6}$ \\
\hline \multicolumn{7}{|c|}{6 months group $(n=35)$} \\
\hline Rank $\times$ self & $59^{* *}$ & -05 & -09 & -22 & $47^{* *}$ & $61^{* *}$ \\
\hline Rank $\times$ boss & 17 & 07 & 17 & 23 & $47 * *$ & $86^{* *}$ \\
\hline Rank $\times$ peers & 16 & 02 & -12 & -15 & $47 * *$ & $65^{* *}$ \\
\hline Sales rank & 00 & 21 & -09 & 25 & $47^{* *}$ & $72^{* *}$ \\
\hline \multicolumn{7}{|c|}{12 months group $(n=34)$} \\
\hline $\operatorname{Rank} \times$ self & 17 & 15 & 03 & $34^{*}$ & $52^{* *}$ & 33 \\
\hline Rank $\times$ boss & $27^{*}$ & -20 & $44^{* *}$ & $31^{*}$ & $52^{* *}$ & $70^{* *}$ \\
\hline Rank $\times$ peers & 09 & 07 & $32^{*}$ & 16 & $52^{* *}$ & $82^{* *}$ \\
\hline Sales rank & $38^{*}$ & -04 & 33 & 22 & $52^{* *}$ & $43^{*}$ \\
\hline
\end{tabular}

${ }^{*} p<.05$ one tail.

$* * p<.01$ one tail. 
TABLE 10

Correlations Between Expectanctes, Role Perceptions, and Abilitites and Performance

\begin{tabular}{|c|c|c|c|c|}
\hline Predictors & Rank $X$ self & Rank $\times$ boss & Rank $\times$ peers & Sales rank \\
\hline \multicolumn{5}{|l|}{ Expectancies: } \\
\hline$(\mathrm{E} \rightarrow \mathrm{P}) \Sigma(\mathrm{P} \rightarrow \mathrm{O})(\mathrm{V})]$ & $.32^{* *}$ & .18 & .08 & .11 \\
\hline \multicolumn{5}{|l|}{ Role perceptions: } \\
\hline Job behavior & .05 & .24 & .15 & -.05 \\
\hline Job success & -.01 & .31 & .32 & -.34 \\
\hline \multicolumn{5}{|l|}{ Abilities: } \\
\hline IQ-total & -.06 & .03 & .03 & .15 \\
\hline IQ-verbal & -.08 & .04 & .04 & .09 \\
\hline IQ-quantitative & -.01 & -.03 & -.01 & .15 \\
\hline \multicolumn{5}{|l|}{ Additive combination: } \\
\hline Expect. + JB + IQ & $.30^{*}$ & $.28 * *$ & .15 & .10 \\
\hline \multicolumn{5}{|l|}{ Multiplicative combination: } \\
\hline Expect. $\times \mathrm{JB} \times \mathrm{IQ}$ & .14 & $.22^{*}$ & .09 & $.22^{*}$ \\
\hline \multicolumn{5}{|l|}{ Multiple correlations: } \\
\hline Expect., JB, IQ & $.32^{* *}$ & $.36^{* *}$ & $.34^{* *}$ & $.53^{* *}$ \\
\hline
\end{tabular}

pectancies and the effort rankings, relatively little support is found for the hypothesized relationship.

\section{Predicting Job Performance}

Table 10 shows the correlations between a number of predictors and performance. In these data, role perceptions tend to be the best predictors of the performance rankings. Neither the additive combination nor the multiplicative one correlates very highly with performance. Finally, the multiple correlation is significant, but not bigh.

\section{DISCUSSION}

The results provide mixed support for expectancy theory. The significant correlations found between job behavior and some of the expectancy type attitude measures provide support for it. However, the failure of the results to show that the data combinations specified by the theory represent an improvement over simple expectancy attitude predictors of performance does not. The results give some indication of which combinations are best, but they don't answer all the questions about expectancy theory that need to be answered.

With respect to the internal structure of the expectancy model, the results do not indicate that weighting expectancy items by valence items 
increases the predictability of behavior. This in not a unique finding, for other studies have also found that valence attitudes don't increase predictability. Still, it is too early to drop the concept of valence from the expectancy approach. First of all, studies (e.g., Porter \& Lawler, 1968) have found that valence measures do increase the relationship between expectancy attitudes and performance. It is also not clear whether the negative results are due to problems with the measure or to the fact that valence doesn't influence motivation as stated by expectancy theory. Self-report measures of valence are of questionable validity because they are prone to such biasing influences as social desirability and to people simply not being aware of what is important to them. Until measures of more certain validity are developed, there will be a question as to how to test predictions concerning the impact of valence.

The failure of the valence measure to increase predictability may also have been due to the particular type of outcomes that were included in the study. Their valence turned out to be consistently high. With this restricted variance in the valence of outcomes, it should not be surprising that weighting the outcome measures by them had little effect on the ability of the expectancy attitudes to predict performance. In this context it is important to note that the unweighted and the weighted $(\mathrm{E} \rightarrow \mathrm{P}) \quad \Sigma(\mathrm{P} \rightarrow \mathrm{O})$ measures correlated almost perfectly with each other providing further evidence that in this situation weighting by valence was essentially equivalent to weighting by a constant.

The data do show that the $(\mathrm{E} \rightarrow \mathrm{P}) \Sigma(\mathrm{P} \rightarrow \mathrm{O})$ combination is the best predictor of performance, but it is not significantly better than either the $(\mathrm{E} \rightarrow \mathrm{P})$ or $\Sigma(\mathrm{P} \rightarrow \mathrm{O})$ measure alone. Still the subjects did seem to distinguish between the two types of expectancies since they did not correlate highly and they both are significantly related to performance in some instance.

The results of the factor analysis show that the subjects distinguish between expectancies involving intrinsically and extrinsically rewarding outcomes. Interestingly the intrinsic reward expectancies correlated most highly with performance. Previous studies which have asked subjects to simply rate the importance of rewards have sometimes gotten intrinsic and extrinsic factors (Vroom, 1964); however, this is the first time these two factors have been found when subjects have been asked to make expectancy type ratings.

The results of the cross-lagged correlational analysis show only limited support for the causal predictions of expectancy theory. The positive results were obtained in the six-months group rather than in the twelve-months group. In this organization some rewards are related 
to performance and performance is rather quickly and easily measured. Further, changes in motivation are quickly reflected in performance. In this context it is not surprising that motivational attitudes and beliefs do not predict performance twelve months later; even six months time lag may be too long since motivation could be expected to influence performance more rapidly than this.

The significant $r_{3}$ correlations that did appear in the twelve months group may reflect the operation of a feedback loop. It makes sense that after twelve months the kind of performance a person has demonstrated and the organization's response to it may have influenced expectancy beliefs. The issue of how expectancy type beliefs develop and change has been the subject of very little research. It would seem to be an important issue and one that certainly is deserving of more research than has been done so far. At this point it would also seem that more research is needed on how long the time lag is between changes in expectancy beliefs and the resultant changes in behavior.

In neither sample are the correlations between the expectancy attitudes and effort high. This study like the others which have tested expectancy theory did not measure the attractiveness of various levels of performance. The model predicts that individuals will pick that level of performance which is most attractive. Thus, knowing how attractive good performance is to individuals gives some idea how likely they are to perform well because on the average people for whom it is very attractive should be better performers than people for whom it is less attractive. However, the best prediction should be obtained by looking at each individual and comparing how attractive good performance is to him in comparison to other levels of performance. This is the only way to determine which level of performance is most attractive.

The results provide little support for the argument that a multiplicative combination of ability, role perceptions, and expectancy beliefs is the best predictor of job performance. The results do show that some combination of these factors can significantly predict performance. The relatively low correlation of the ability measure with performance makes it difficult to reach any strong conclusion about how it combines with role perceptions and motivation to determine performance. It was hoped that the measure of intellectual ability that was used would correlate significantly with performance. Unfortunately, it, like many other intellectual ability measures, does not seem to be a good predictor of performance in sales type jobs (Ghiselli, 1966). To adequately test the model, a situation is needed where an ability measure can be found that is significantly related to performance.

The results show that expectancy type beliefs can predict behavior but 
they do not show that many of the more complex predictions that are generated by the theory are valid. Still, it is too early to conclude that some of the more complex aspects of the model are invalid. In most cases it is difficult to tell whether the lack of support is due to the incorrectness of the model or to methodological problems that are associated with testing certain parts of it. At this point it seems that the theory has become so complex that it has exceeded the measures which exist to test it. This has two implications. First, if the theory is to be tested, new measures must be developed. Second, when it is necessary to measure motivation, it probably is best to measure just a few simple expectancy attitudes since these seem to work as well as the more complex combinations.

\section{REFERENCES}

Blalock, H. M. Four variable causal model and partial correlation. American Journal of Sociology, 1962, 68, 182-194.

Campbetu, D. T., \& Fiske, D. W. Convergent and discriminant validation by the multitrait-multimethod matrix. Psychological Bulletin, 1959, 56, 81-105.

Campbelt, D. T., \& Stanley, J. C. Experimental and quasi-experimental designs for research on teaching. In N. L. Gage (Ed.) Handbook of research on teaching. New York: Rand McNally, 1963.

Campbell, J. P., Dunnette, M. D., Lawler, E. E., \& Weick, K. E. Managerial behavior, performance and effectiveness. New York: McGraw-Hill, 1970.

Evans, M. G. The effects of supervisory behavior on the path-goal relationship. Organizational Behavior and Human Performance, 1970, 5, 277-298.

Galbraith, J., \& Cummings, L. L. An empirical investigation of the motivational determinants of task performance: Interactive effects between instrumentalityvalence and motivation-ability. Organizational Behavior and Human Performance, 1967, 2, 237-257.

GaviN, J. F. Ability, effort and role perceptions as antecedents of job performance. Experimental Publication System, 1970, 5, Ms. No. 190A.

Georgopoulos, B. S., Mahoney, G. M., \& Jones, N. W. A path-goal approach to productivity. Journal of Applied Psychology, 1957, 41, 345-353.

GHiselli, E. A. The validity of occupational aptitude tests. New York: Wiley, 1966.

Goodman, P. S., Rose, J. H., \& Furcon, J. E. Comparison of motivational antecedents of the work performance of scientists and engineers. Journal of $A p$ plied Psychology, 1970, 54, 491-495.

GraEN, G. Instrumentality theory of work motivation: Some experimental results and suggested modifications. Journal of Applied Psychology Monograph, 1969, $53,1-25$.

Hackman, J. R., \& Lawler, E. E. Employee reactions to job characteristics. Joumal of Applied Psychology Monograph, 1971, 55, 259-286.

HACKMAN, J. R., \& Porter, L. W. Expectancy theory predictions of work effectiveness. Organizational Behavior and Human Performance, 1968, 3, 417-426.

Heneman, H. G., \& Schwab, D. P. Evaluation of research on expectancy theory prediction of employee performance. Psychological Bulletin, 1972, 78, 1-9.

House, R. J. A path goal theory of leader effectiveness. Administrative Sciences Quarterly, 1971, 16, 321-339. 
KAISER, H. R. The varimax criterion for analytic rotation in factor analyses. Psychometrika, 1958, 23, 187-200.

LAwlen, E. E. Managers' job performance and their attitudes toward their pay. Unpublished doctoral dissertation, University of California, Berkeley, 1964.

LAwlen, E. E. Ability as a moderator of the relationship between job attitudes and job performance. Personnel Psychology, 1966(a), 19, 153-164.

Lawler, F. E. Managers' attitudes toward how their pay is and should be determined. Journal of Applied Psychology, 1966(b), 50, 273-279.

LAwLER, E. E. A correlational-causal analysis of the relationship between expectancy attitudes and job performance. Journal of Applied Psychology, 1968, 52, 462-468.

Lawler, E. E. Pay and organizational effectiveness: $A$ psychological view. New York: McGraw-Hill, 1971.

Lawler, E. E., \& PORTER, L. W. Antecedent attitudes of effective managerial performance. Organizational Behavior and Human Performance, 1967, 2, 122-142.

Lawler, E. E., \& SuTtle, J. L. A causal correlational test of the need hierarchy concept. Organizational Behavior and Human Performance, 1972, 7, 265-287.

MaIER, N. R. Psychology in Industry. Boston: Houghton-Mifflin, 1955. 2nd Ed.

Mttchell, T. R., \& Albright, D. Expectancy theory predictions of job satisfaction, job effort, job performance, and retention of naval aviation officers. Organizational Behavior and Human Performance, 1972, 8, 1-20.

Pelz, D. C., \& Andrwws, F. M. Detecting causal priorities in panel study data. American Sociological Review, 1964, 29, 836-848.

Porter, L. W. A study of perceived need satisfaction in bottom and middle management jobs. Journal of Applied Psychology, 1961, 45, 1-10.

Porter, L. W. Job attitudes in management: I. Perceived deficiencies in need fulfillment as a function of job level. Journal of Applied Psychology, 1962, 46, 375-384.

Porter, L. W. Organizational patterns of managerial job attitudes. New York: American Foundation for Management Research, Inc., 1964.

Ponter, L. W., \& LAWLen, E. E. Managerial attitudes and performance. Homewood, IL: Irwin, 1968.

Riesman, P. The lonely crowd. New Haven, CT: Yale Univ. Press, 1950.

Rozelle, R. M., \& Campbelt, D. T. More plausible rival hypotheses in the crosslagged panel correlative technique. Psychological Bulletin, 1969, 71, 74-80.

Schuster, J. R., Clark, B., \& Rogers, M. Testing portions of the Porter and Lawler model regarding the motivational role of pay. Journal of Applied Psychology, 1971, 55, 187-195.

Simon, H. A. Spurious correlation: A causal interpretation. Journal of the American Statistical Association, 1954, 49, 467-479.

SpItzRr, M. E. Goal-attainment, job satisfaction and behavior. (Doctoral dissertation, New York University) Ann Arbor, MI: University Microfilms, 1964. No. $64-10,048$.

Thurstone, T. G., \& Thurstone, L. L. Thurstone Tests of Mental Alertness: Examiner Manual. Chicago, IL: Science Research Association, 1952.

VRoom, V. H. Work and motivation. New York: Wiley, 1964.

Whyte, W. H. The organization man. New York: Simon \& Schuster, 1956.

ReCEIVED: June 2, 1972 